\title{
Sequence Decoding of 1D to 2D Self-Assembling Cyclic Peptides
}

\author{
Sandra Díaz ${ }^{+}$, Ignacio Insua ${ }^{+}$, Ghibom Bhak and Javier Montenegro*
}

Centro Singular de Investigación en Química Biolóxica e Materiais Moleculares (CIQUS), Departamento de Química Orgánica. Universidade de Santiago de Compostela. Santiago de Compostela, 15782, Spain.

+ These authors contributed equally to this work.

E-mail: javier.montenegro@usc.es

\section{Supporting Information}

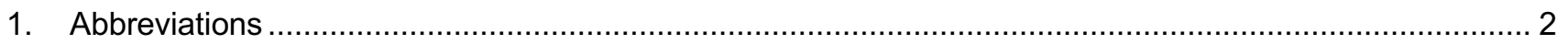

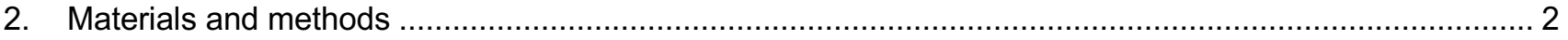

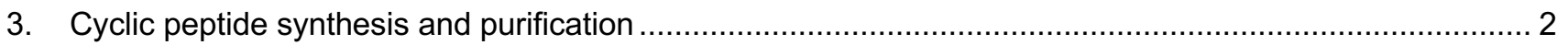

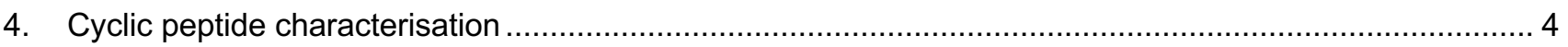

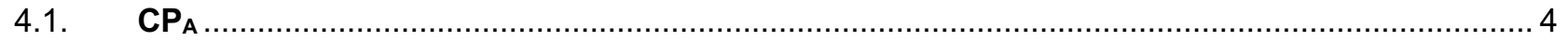

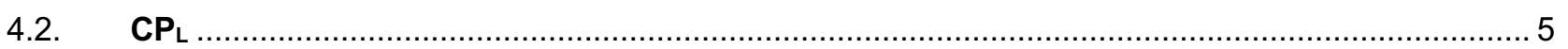

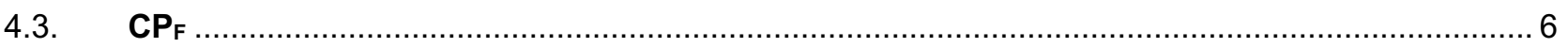

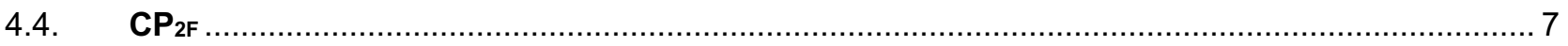

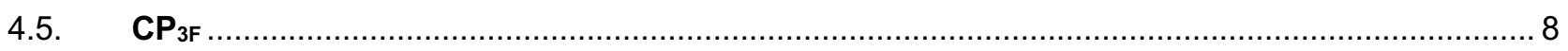

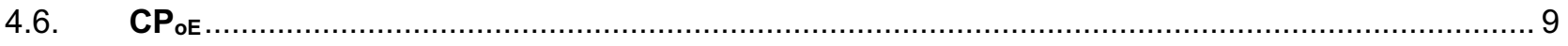

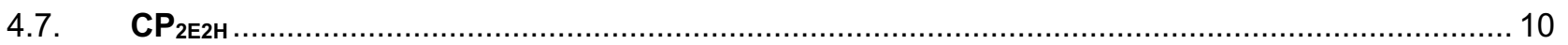

4.8.

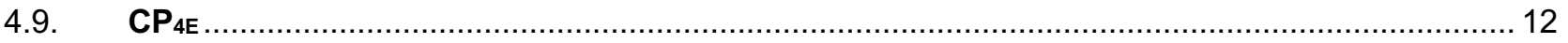

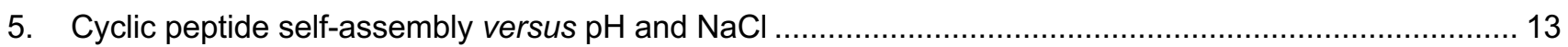




\section{Abbreviations}

ACN: acetonitrile, AFM: atomic force microscopy, All: allyl, CP: cyclic peptide, DCM: dichloromethane, DIEA: $\mathrm{N}, \mathrm{N}$-diisopropylethylamine, DMF: $\mathrm{N}, \mathrm{N}$-dimethylformamide, ESI: electrospray ionisation, Fmoc: 9fluorenylmethoxycarbonyl, HOBt: hydroxybenzotriazole, HR-MS: high resolution mass spectrometry, HPLC-

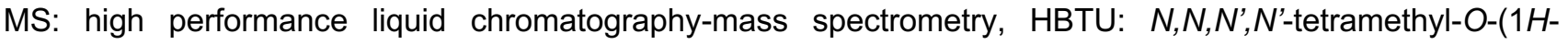
benzotriazol-1-yl)uronium hexafluorophosphate, NMR: nuclear magnetic resonance spectroscopy, OAc: acetate, Ph: phenyl, PyAOP: (7-azabenzotriazol-1-yloxy) tripyrrolidinophosphonium hexafluorophosphate, SPPS: solid phase peptide synthesis STEM: scanning transmission electron microscopy, TFA: trifluoroacetic acid, ThT: thioflavin T, TIS: triisopropylsilane.

\section{Materials and methods}

Chemical reagents were acquired from Acros Organics, Aldrich, Fisher Scientific, Iris Biotech and Novabiochem. Dichloromethane was dried under reflux over calcium hydride. $\mathrm{D}_{2} \mathrm{O}$ was purchased from EMD Millipore. Glass slides for fluorescence microscopy were obtained from Ibidi (Cat\# 80827). TEM grids (Cu carbon type-B, 300 mesh) and PELCO ${ }^{\circledR}$ mica discs for AFM were acquired from Ted Pella. ${ }^{1} \mathrm{H}$ NMR spectra were recorded on a Varian $300 \mathrm{MHz}$ spectrometer. Chemical shifts are reported in ppm $(\delta)$ referenced to $D_{2} O$ 's residual signal $(\delta=$ 4.79). HPLC-MS analyses were carried out on an Agilent 1260 Infinity II fitted with an Agilent SB-C18 column and connected to a 6120 Quadrupole MS detector. HR-MS was acquired on a Bruker MicroTOF. Epifluorescence micrographs were taken with a Nikon Eclipse Ti (60x immersion objective, Excitation=475/35 $\mathrm{nm}$; Emission=530/43 nm). STEM images were acquired on a FESEM Ultra plus (Zeiss) operating at $20 \mathrm{kV}$ from unstained samples. AFM analysis was carried out on a NX-10 microscope in non-contact mode and using ACTA $10 \mathrm{M}$ cantilevers (Park Systems).

\section{Cyclic peptide synthesis and purification}

Cyclic peptides were prepared manually in solid phase. Rink Amide resin was swollen in DMF for 30 min and then treated with piperidine $20 \% \mathrm{v} / \mathrm{v}$ in DMF ( $3 \mathrm{~mL}$ ) to remove the Fmoc protecting group. The resin was washed with DMF (3 x $3 \mathrm{~mL})$ and a solution of Fmoc-L-Glu(OH)-OAll (163.6 mg, $0.1 \mathrm{mmol})$, HBTU (132.5 mg, 0.35 $\mathrm{mmol}$ ) and DIEA (95 $\mathrm{LL}, 0.6 \mathrm{mmol})$ in DMF $(3 \mathrm{~mL})$ was added over the resin and shaken for $1 \mathrm{~h}$. Then the mixture was filtered and washed with DMF $(3 \times 3 \mathrm{~mL})$ and DCM $(3 \times 3 \mathrm{~mL})$. We followed cycles of Fmoc removal (2 $\mathrm{mL}$ of piperidine $20 \% \mathrm{v} / \mathrm{v}$ in DMF for $15 \mathrm{~min}$ ) and amino acid coupling $(0.4 \mathrm{mmol}$ of amino acid, $0.35 \mathrm{mmol}$ HBTU and $0.6 \mathrm{mmol}$ DIEA in DMF for $30 \mathrm{~min}$ ) with their respective washes (DMF $3 \times 3 \mathrm{~mL}$ ).

For OAll removal, the resin was washed with DMF and DCM $(3 \times 3 \mathrm{~mL})$ and then reacted with a solution of $\mathrm{PPh}_{3}$ (39.3 mg, $0.15 \mathrm{mmol}), N$-methylmorpholine $(110 \mu \mathrm{L}, 0.01 \mathrm{mmol})$ and phenylsilane $(123 \mu \mathrm{L}, 1.0 \mathrm{mmol})$ and $\mathrm{Pd}(\mathrm{OAc})_{2}(6.7 \mathrm{mg}, 0.03 \mathrm{mmol})$ in dry DCM $(4 \mathrm{~mL})$ overnight $(16-20 \mathrm{~h})$. The resin was then washed with DCM (3 $\times 3 \mathrm{~mL})$ and DIEA in DMF ( $2 \% \mathrm{v} / \mathrm{v}, 3 \times 3 \mathrm{~mL})$, and soaked in a solution of sodium diethyldithiocarbamate $(0.5 \%$ $w / v$ in DMF, $2 \times 3 \mathrm{~mL}$ ) for 30 min to remove all traces of Pd. Finally, the resin was stirred with piperidine/DMF $(20 \% \mathrm{v} / \mathrm{v}, 3 \mathrm{~mL})$ for $30 \mathrm{~min}$ for $\mathrm{N}$-terminal Fmoc removal. 
Cyclisation was carried out by reacting a solution of PyAOP $(208.6 \mathrm{mg}, 0.4 \mathrm{mmol})$ and DIEA $(95.1 \mathrm{~mL}, 0.6$ $\mathrm{mmol})$ in DMF $(3 \mathrm{~mL})$ for $2 \mathrm{~h}$. After washing with DMF $(3 \times 3 \mathrm{~mL})$ and DCM $(3 \times 3 \mathrm{~mL})$, the cyclisation was repeated twice more in the same conditions.

The peptide was cleaved from the resin by addition of a freshly prepared TFA cocktail ( $4 \mathrm{~mL}$, TFA:DCM: $\mathrm{H}_{2} \mathrm{O}: T I S$, 0.9:0.05:0.025:0.025), this mixture was shaken for $2 \mathrm{~h}$ and then filtered. The resin was washed with TFA (0.5 $\mathrm{mL}$ ) twice and concentrated under nitrogen. The concentrated reaction crude was precipitated dropwise into 40 $\mathrm{mL}$ of cold diethyl ether under stirring. The resulting suspension was centrifuged and the pellet was then dissolved in a 1:0.25 mixture of MilliQ $\mathrm{H}_{2} \mathrm{O}: \mathrm{ACN}$ and purified by semipreparative HPLC using a Phenomenex Luna $\mathrm{C} 18100 \AA$ column [gradient of $\mathrm{A}\left(\mathrm{H}_{2} \mathrm{O}+0.1 \% \mathrm{v} / \mathrm{v}\right.$ TFA) : $\mathrm{B}(\mathrm{ACN}+0.1 \% \mathrm{v} / \mathrm{v}$ TFA $) \rightarrow 95: 5$ (0 min) to $25: 75$ (30 min)]. Peptide fractions were concentrated in vacuo to remove $A C N$ and TFA and the remaining solution was freeze dried.

A white powder was obtained for all cyclic peptides: $\mathbf{C P}_{\mathbf{A}}$ (35 mg, $36 \%$ ); $\mathbf{C P}_{\mathbf{L}}\left(40 \mathrm{mg}, 40 \%\right.$ ); $\mathbf{C P}_{\mathbf{F}}$ (41 mg, 39 \%); $\mathbf{C P}_{2 \mathrm{~F}}$ (44 mg, $38 \%$ ); $\mathbf{C P}_{3 \mathrm{~F}}$ (39 mg, $35 \%$ ); $\mathbf{C P}_{\mathrm{oE}}\left(41 \mathrm{mg}, 38 \%\right.$ ); $\mathbf{C P}_{2 \mathrm{E} 2 \mathrm{H}}\left(38 \mathrm{mg}, 35 \%\right.$ ); $\mathbf{C P}_{\mathrm{K}}(22 \mathrm{mg}, 21 \%$ ); $\mathrm{CP}_{4 \mathrm{E}}(24 \mathrm{mg}, 22 \%)$.

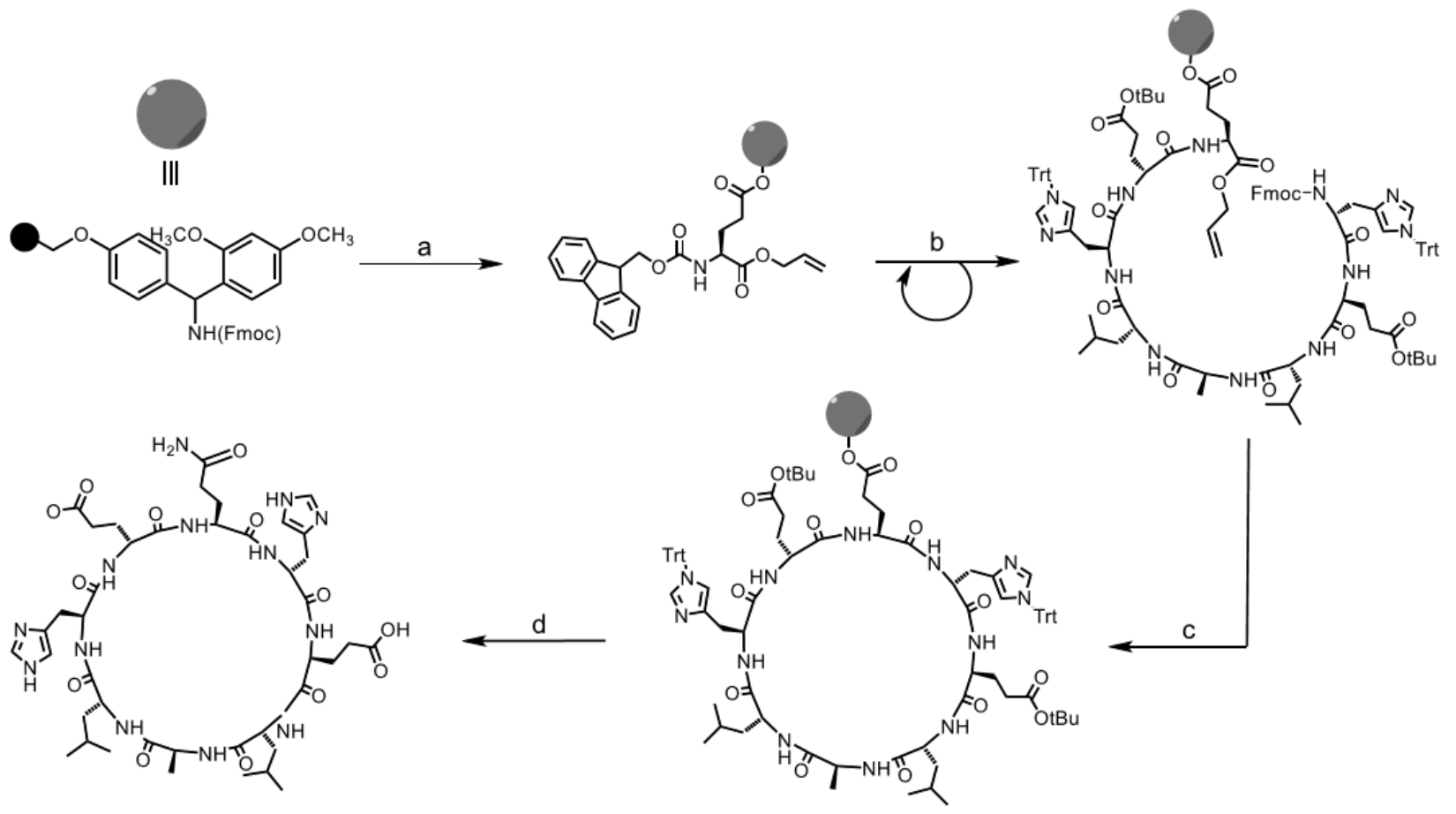

Scheme S1. a) Rink Amide resin functionalisation: i. Piperidine $20 \%$ v/v in DMF, $30 \mathrm{~min}$; ii. Fmoc-L-Glu-OAll, HBTU, DIEA, DMF, 1 h. b) Peptide elongation: i. Piperidine 20\% v/v in DMF, 15 min; ii. Fmoc-amino acid, HBTU, DIEA, DMF, 30 min. (Repeat 7 cycles). c) Cyclisation: i. OAllyl removal: $\mathrm{Pd}(\mathrm{OAc})_{2}, \mathrm{PPh}_{3}$, phenylsilane, 4methylmorpholine, DCM, overnight (16-20 h); ii. Fmoc removal: piperidine 20\% v/v in DMF, $30 \mathrm{~min}$; iii. Peptide cyclisation: PyAOP, DIEA, DMF, 2 h (repeat twice). d) Peptide cleavage: TFA, DCM, $\mathrm{H}_{2} \mathrm{O}, \mathrm{TIS}, 2 \mathrm{~h}$. 


\section{Cyclic peptide characterisation}

\section{1. $\quad \mathrm{CP}_{\mathrm{A}}$}

UHPLC-MS (C18-ESI, +eV) A = $\mathrm{H}_{2} \mathrm{O}+0.1 \%$ TFA; $\mathrm{B}=\mathrm{ACN}+0.1 \%$ TFA; Gradient (A:B): 100:0 (0 min) $\rightarrow$ 25:75 $(21 \mathrm{~min}) ; R_{t}=9.5 \mathrm{~min} ; \mathrm{m} / \mathrm{z}=958.5\left([\mathrm{M}+\mathrm{H}]^{+}\right), 479.8\left([\mathrm{M}+2 \mathrm{H}]^{2+}\right)$.
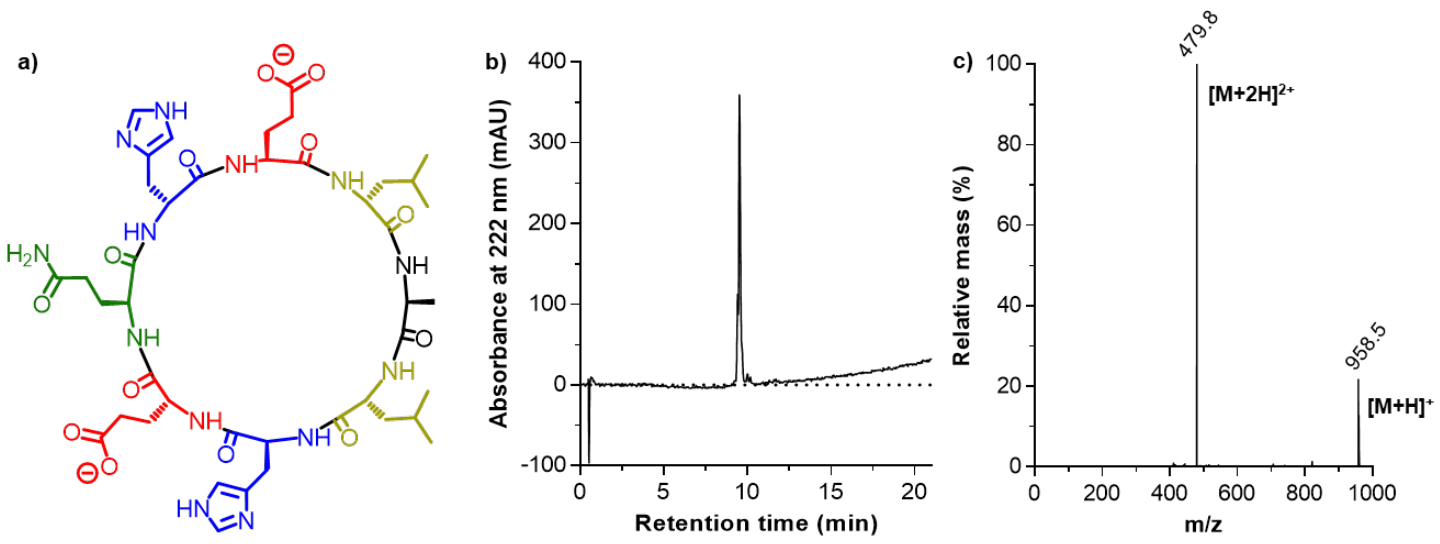

Figure S1. a) Structure of $\mathrm{CP}_{\mathbf{A}}$; b) Chromatogram after purification; c) MS spectrum of the peak.

HR-MS (ESI, +eV) m/z = 958.4741 (calculated for $\left.[M+H]^{+}\right)$; 958.4744 (found).

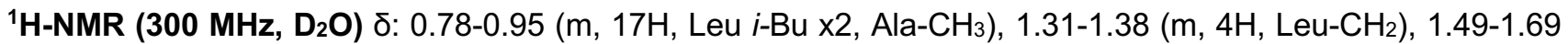
(m, 4H, Glu- $\left.\mathrm{CH}_{2}-\mathrm{x} 2\right), 1.82-2.13$ (m, 4H, Gln x2), 2.27-2.34 (m, 4H, Glu- $\left.\mathrm{CH}_{2}-\mathrm{x} 2\right)$, 3.01-3.43 (m, 4H, His- $\mathrm{CH}_{2-}$ $\mathrm{x} 2)$, 4.17-4.47 (m, 8H, $\left.\mathrm{H}_{\mathrm{a}}\right), 7.22-7.34(\mathrm{~m}, 2 \mathrm{H}, \mathrm{His}-\mathrm{CH}=\mathrm{x} 2), 8.66(\mathrm{~s}, 2 \mathrm{H}, \mathrm{His}-\mathrm{CH}=\mathrm{x} 2) \mathrm{ppm}$.

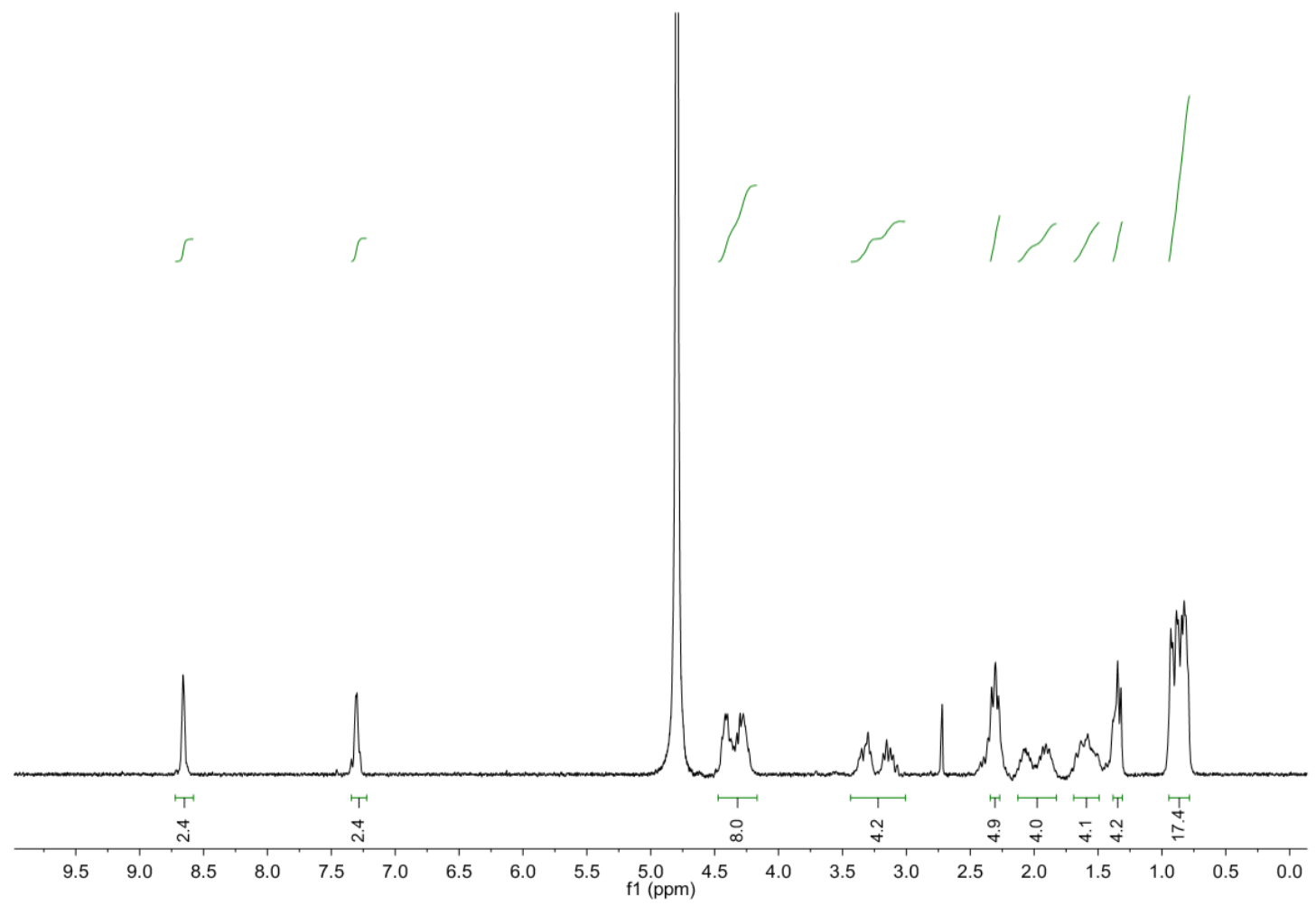

Figure S2. ${ }^{1} \mathrm{H}$ NMR $(300 \mathrm{MHz})$ of $\mathrm{CP}_{\mathrm{A}}$ in $\mathrm{D}_{2} \mathrm{O}$. 


\section{2. $\quad C P_{L}$}

UHPLC-MS (C18-ESI, +eV) A = $\mathrm{H}_{2} \mathrm{O}+0.1 \%$ TFA; $B=A C N+0.1 \%$ TFA; Gradient (A:B): 100:0 (0 min) $\rightarrow$ 25:75 $(21 \mathrm{~min}) ; R_{t}=11.1 \mathrm{~min} ; \mathrm{m} / \mathrm{z}=1000.5\left([\mathrm{M}+\mathrm{H}]^{+}\right), 500.8\left([\mathrm{M}+2 \mathrm{H}]^{2+}\right)$.
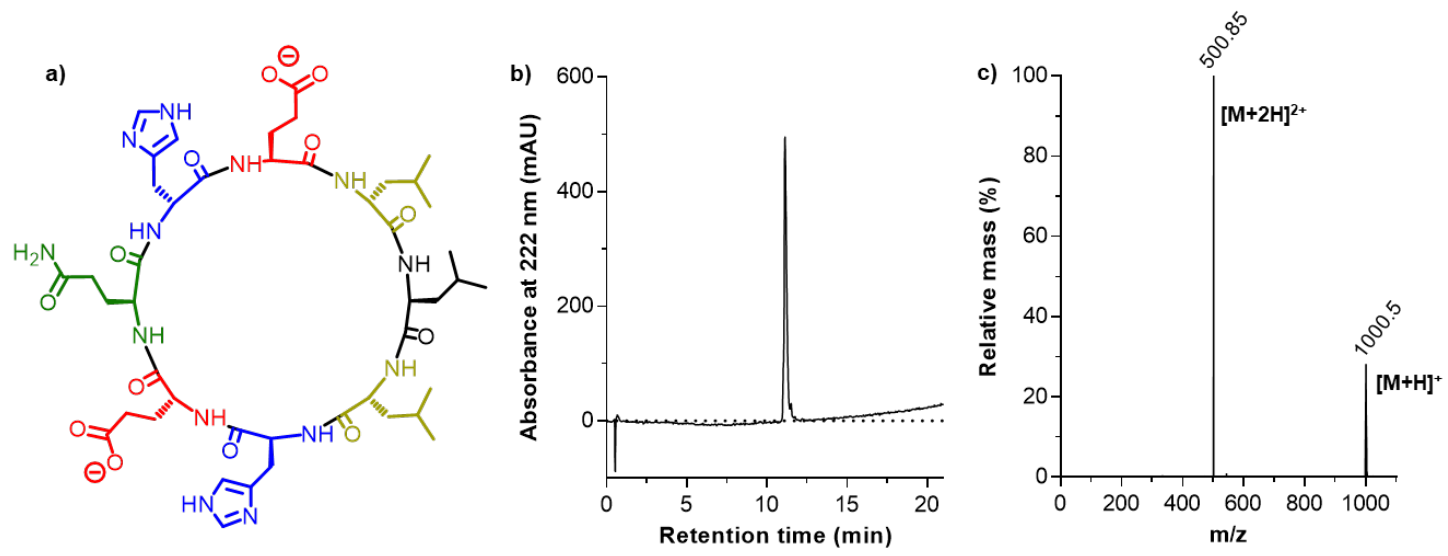

Figure S3. a) Structure of $\mathrm{CP}_{\mathrm{L}}$; b) Chromatogram after purification; c) MS spectrum of the peak.

HR-MS $(E S I,+e V): m / z=1000.5211$ (calculated for $\left.[M+H]^{+}\right) ; 1000.5206$ (found).

${ }^{1} \mathrm{H}-N M R\left(300\right.$ MHz, $\left.\mathbf{D}_{2} \mathrm{O}\right)$ ס: 0.78-0.95 (m, 27H, Leu x3), 1.49-2.37 (m, 12H, Glu x2, Gln), 3.01-3.44 (m, 4H, His$\left.\mathrm{CH}_{2-} \mathrm{x} 2\right), 4.18-4.76\left(\mathrm{~m}, 8 \mathrm{H}, \mathrm{H}_{\alpha}\right), 7.28-7.31(\mathrm{~m}, 2 \mathrm{H}, \mathrm{His}-\mathrm{CH}=\mathrm{x} 2), 8.66(\mathrm{~s}, 2 \mathrm{H}, \mathrm{His}-\mathrm{CH}=\mathrm{x} 2) \mathrm{ppm}$.

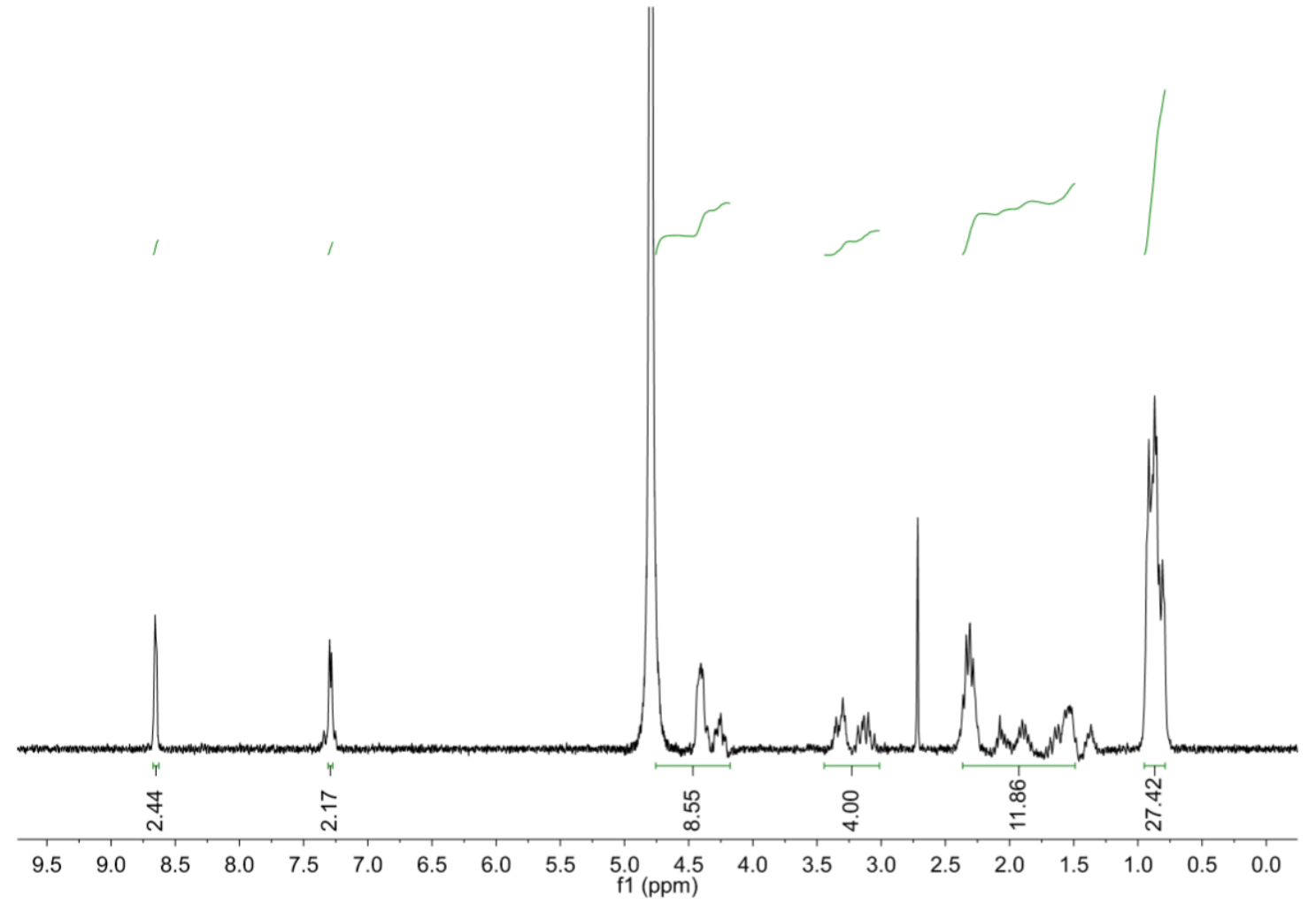

Figure S4. ${ }^{1} \mathrm{H}$ NMR $(300 \mathrm{MHz})$ of $\mathrm{CPL}$ in $\mathrm{D}_{2} \mathrm{O}$. 


\section{3. $\mathrm{CP}_{\mathrm{F}}$}

UHPLC-MS (C18-ESI, +eV) A = $\mathrm{H}_{2} \mathrm{O}+0.1 \%$ TFA; $B=A C N+0.1 \%$ TFA; Gradient (A:B): 100:0 (0 min) $\rightarrow$ 25:75 $(21 \mathrm{~min}) ; R_{t}=11.4 \mathrm{~min} ; \mathrm{m} / \mathrm{z}=1034.5\left([\mathrm{M}+\mathrm{H}]^{+}\right), 517.8\left([\mathrm{M}+2 \mathrm{H}]^{2+}\right)$.
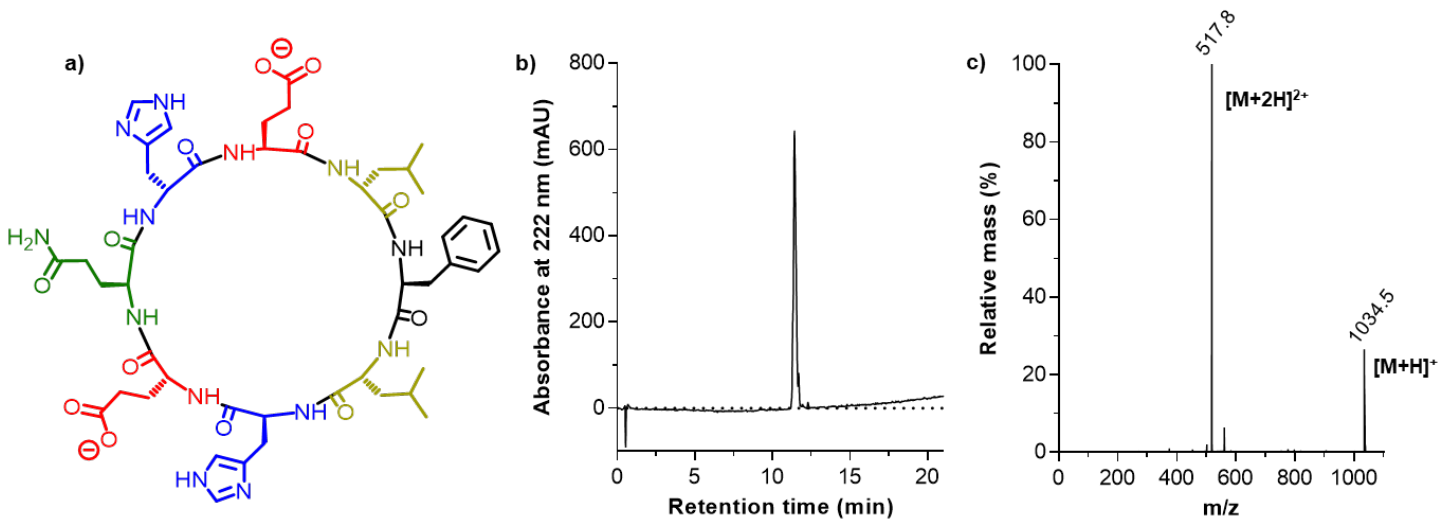

Figure S5. a) Structure of $\mathrm{CP}_{\mathrm{F}}$; b) Chromatogram after purification; c) MS spectrum of the peak.

HR-MS (ESI, +eV): m/z = 1034.5054 (calculated for $[\mathrm{M}+\mathrm{H}]^{+}$); 1034.5048 (found).

${ }^{1} \mathrm{H}-\mathrm{NMR}\left(300 \mathrm{MHz}, \mathrm{D}_{2} \mathrm{O}\right)$ ס: 0.67-0.90 (m, 16H, Leu i-Bu x2, Leu-CH2- x2), 1.22-1.38 (m, 2H, Leu-CH- x2), 1.692.41 (m, 12H, Glu x2, Gln), 2.88-3.25 (m, 4H, His- $\left.\mathrm{CH}_{2}-\mathrm{x} 2\right)$, 3.25-3.42 (m, 2H, Phe- $\left.\mathrm{CH}_{2-}\right), 4.01-4.68(\mathrm{~m}, 8 \mathrm{H}, \mathrm{H})$, 7.19-7.35 (m, 7H, His-CH= x2, Phe-CH= x2), $8.63(\mathrm{~s}, 2 \mathrm{H}$, His- $\mathrm{CH}=\mathrm{x} 2) \mathrm{ppm}$.

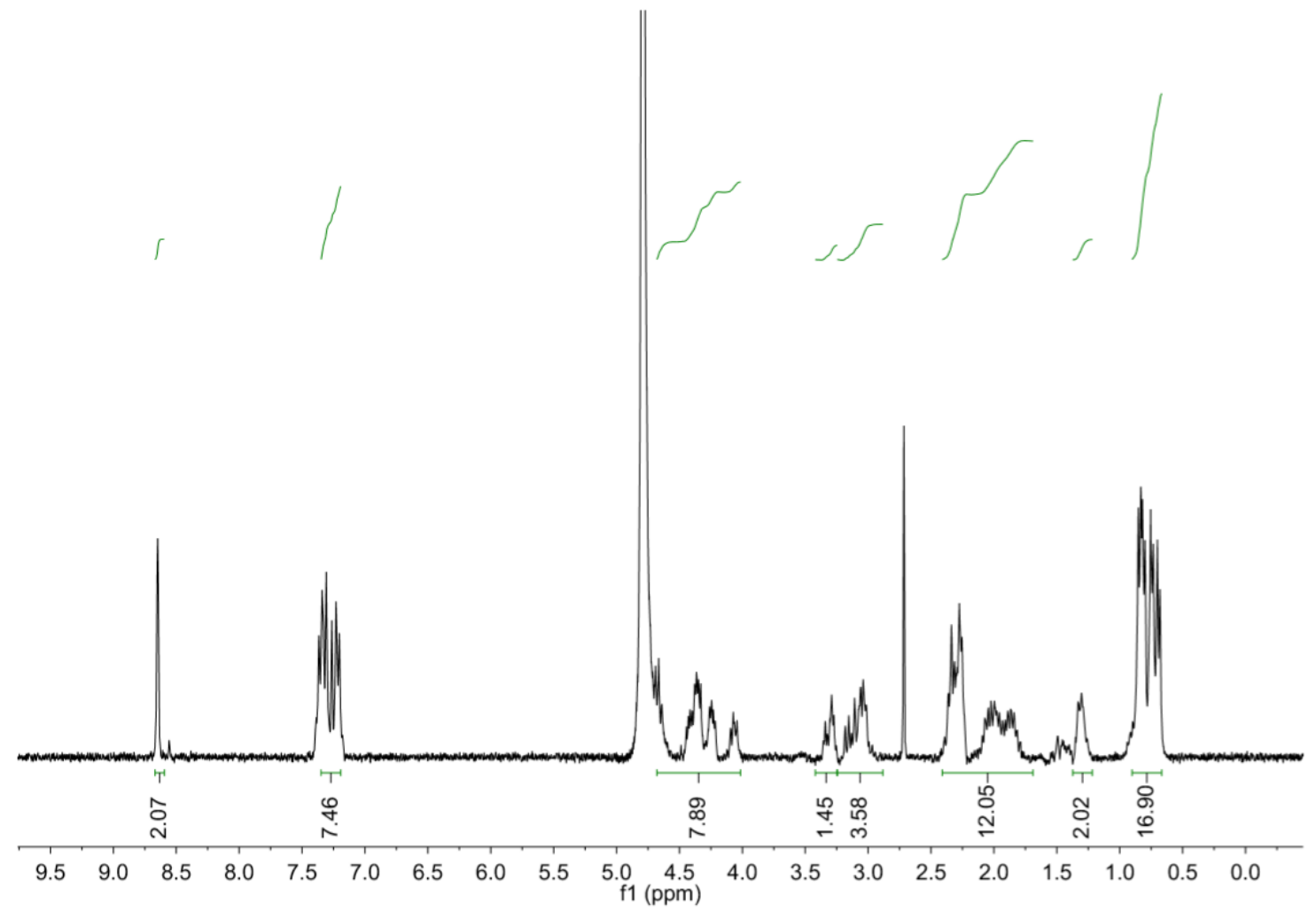

Figure S6. ${ }^{1} \mathrm{H}$ NMR $(300 \mathrm{MHz})$ of $\mathrm{CP}_{\mathrm{F}}$ in $\mathrm{D}_{2} \mathrm{O}$. 


\section{4. $\quad \mathrm{CP}_{2 \mathrm{~F}}$}

UHPLC-MS (C18-ESI, +eV) A = $\mathrm{H}_{2} \mathrm{O}+0.1 \%$ TFA; $B=A C N+0.1 \%$ TFA; Gradient (A:B): 100:0 (0 min) $\rightarrow$ 25:75 $(21 \mathrm{~min}) ; R_{t}=11.9 \mathrm{~min} ; \mathrm{m} / \mathrm{z}=1141.5\left([\mathrm{M}+\mathrm{H}]^{+}\right), 571.3\left([\mathrm{M}+2 \mathrm{H}]^{2+}\right)$.
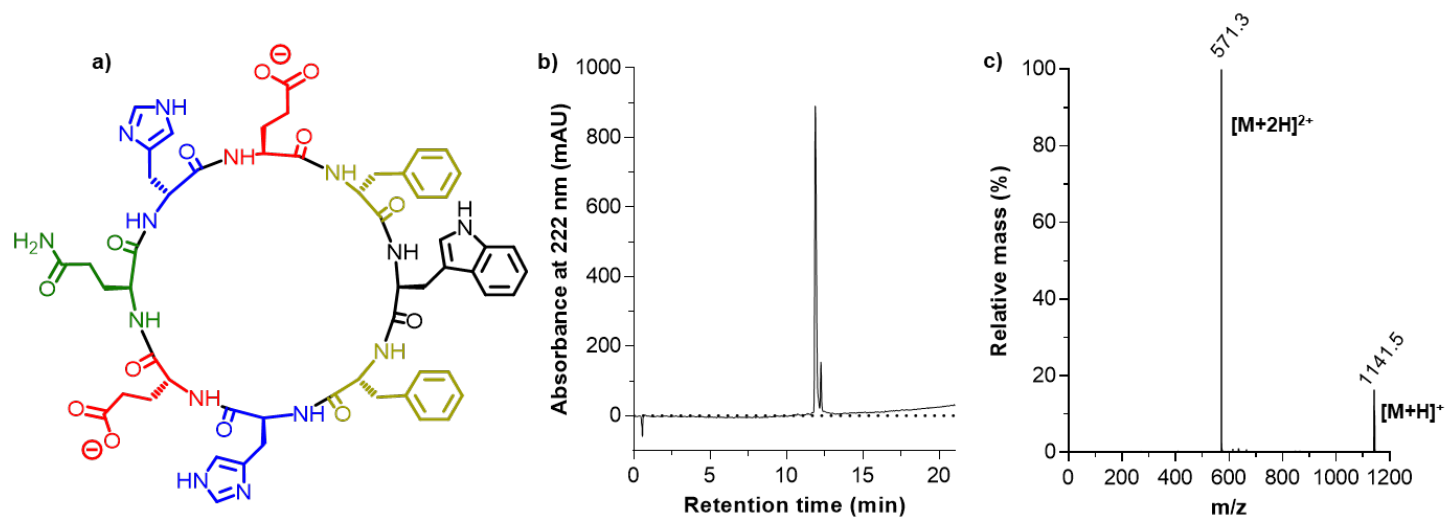

Figure S7. a) Structure of $\mathrm{CP}_{2 \mathrm{~F}}$; b) Chromatogram after purification; c) MS spectrum of the peak.

HR-MS (ESI, +eV): m/z = 1141.4850 (calculated for $\left.[\mathrm{M}+\mathrm{H}]^{+}\right) ; 1141.4845$ (found):

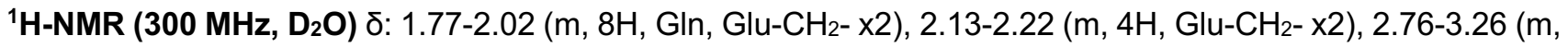
$10 \mathrm{H}$, Phe- $\mathrm{CH}_{2-} \mathrm{x2}$, Trp- $\mathrm{CH}_{2-}$, His- $\left.\mathrm{CH}_{2}-\mathrm{x} 2\right), 4.11-4.70\left(\mathrm{~m}, 8 \mathrm{H}, \mathrm{H}_{\alpha}\right), 7.02-7.45(\mathrm{~m}, 17 \mathrm{H}, \mathrm{Phe}-\mathrm{CH}=\mathrm{x} 15$, His- $\mathrm{CH}=$ $\mathrm{x} 2)$, 8.53-8.65 (m, 2H, His-CH= x2) ppm.

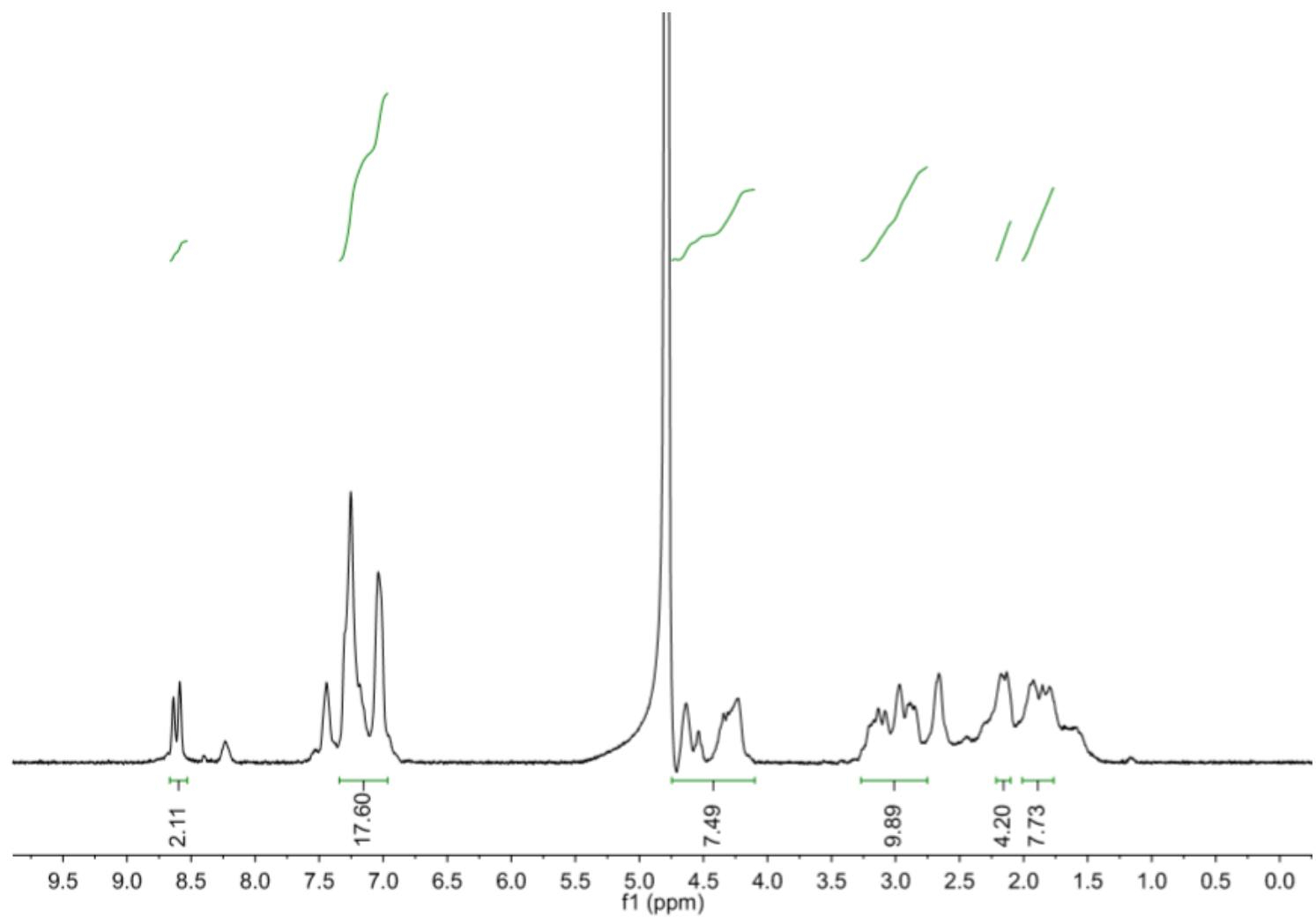

Figure S8. ${ }^{1} \mathrm{H}$ NMR $(300 \mathrm{MHz})$ of $\mathrm{CP}_{2 \mathrm{~F}}$ in $\mathrm{D}_{2} \mathrm{O}$. 


\section{5. $\quad \mathrm{CP}_{3 \mathrm{~F}}$}

UHPLC-MS (C18-ESI, +eV) A = $\mathrm{H}_{2} \mathrm{O}+0.1 \%$ TFA; $B=A C N+0.1 \%$ TFA; Gradient (A:B): 100:0 $(0$ min $) \rightarrow 25: 75$ $(21 \mathrm{~min}) ; R_{t}=12.2 \mathrm{~min} ; \mathrm{m} / \mathrm{z}=1102.5\left([\mathrm{M}+\mathrm{H}]^{+}\right), 551.8\left([\mathrm{M}+2 \mathrm{H}]^{2+}\right)$.
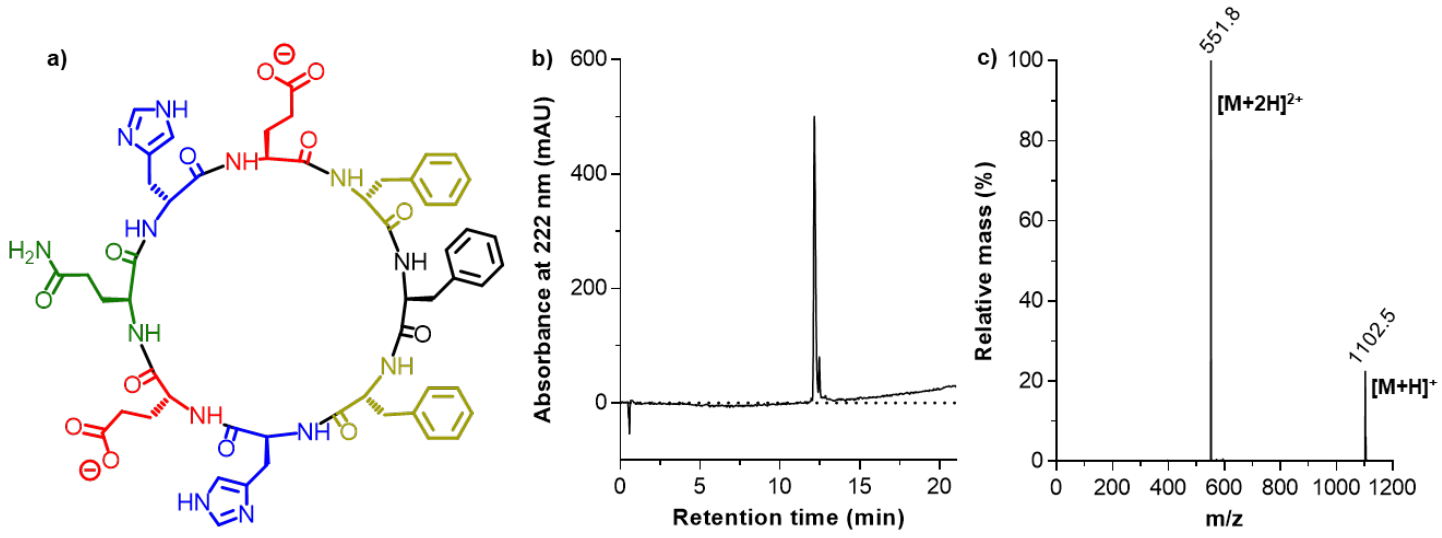

Figure S9. a) Structure of $\mathrm{CP}_{3 \mathrm{~F}}$; b) Chromatogram after purification; c) MS spectrum of the peak.

HR-MS (ESI, +eV): m/z = 1102.4741 (calculated for $\left.[M+H]^{+}\right), 1102.4737$ (found).

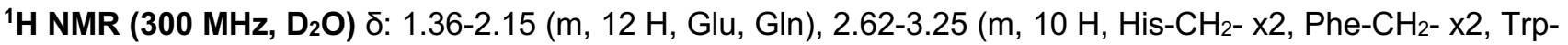
$\left.\mathrm{CH}_{2-}\right)$, 4.19-4.80 (m, 8H, $\left.\mathrm{H}_{\alpha}\right), 6.98-7.41(\mathrm{~m}, 17 \mathrm{H}$, Phe $\times 3$, His x2), $8.62(\mathrm{~s}, 2 \mathrm{H}, \mathrm{His} \times 2)$ ppm.

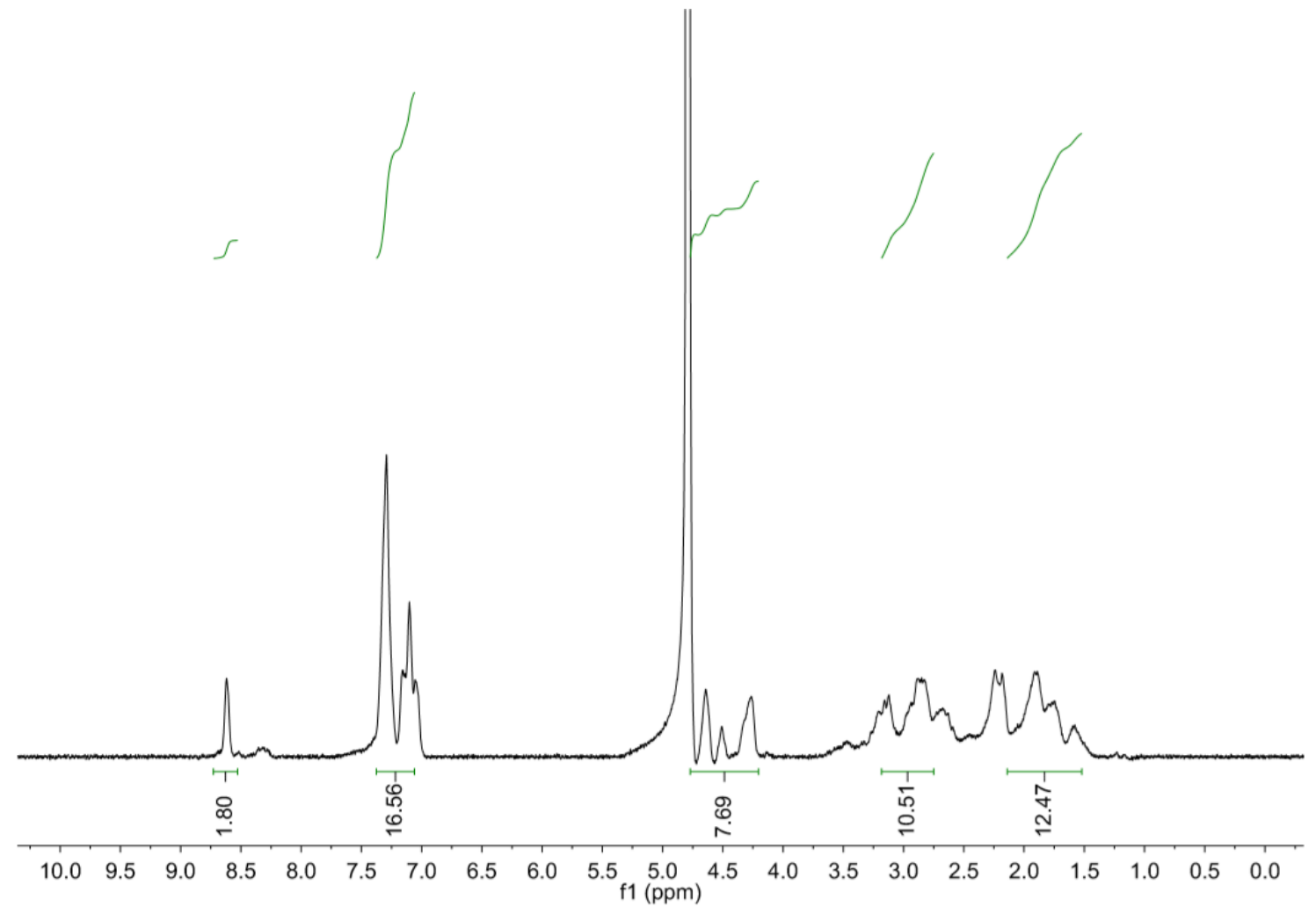

Figure S10. ${ }^{1} \mathrm{H}$ NMR $(300 \mathrm{MHz})$ of $\mathrm{CP}_{3 \mathrm{~F}}$ in $\mathrm{D}_{2} \mathrm{O}$. 


\section{6. $\quad \mathrm{CP}_{\mathrm{OE}}$}

UHPLC-MS (C18-ESI, +eV) A = $\mathrm{H}_{2} \mathrm{O}+0.1 \%$ TFA; $B=A C N+0.1 \%$ TFA; Gradient (A:B): 100:0 (0 min) $\rightarrow$ 25:75 $(21 \mathrm{~min}) ; R_{t}=10.9 \mathrm{~min} ; \mathrm{m} / \mathrm{z}=1073.5\left([\mathrm{M}+\mathrm{H}]^{+}\right), 537.3\left([\mathrm{M}+2 \mathrm{H}]^{2+}\right)$.
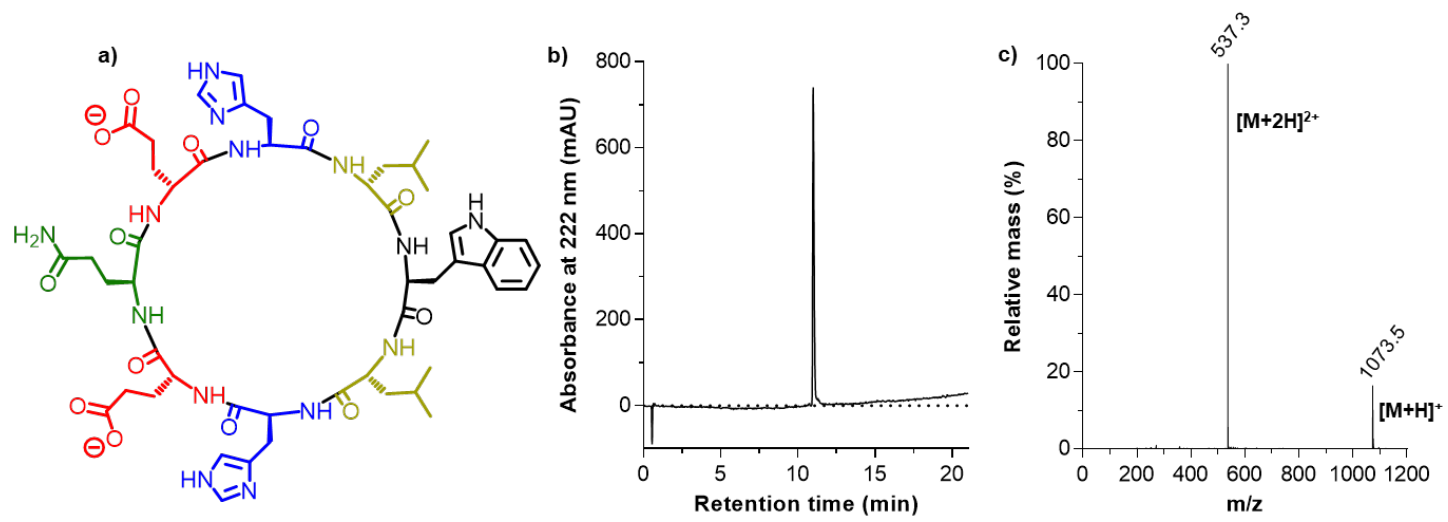

Figure S11. a) Structure of $\mathrm{CP}_{\mathrm{oE}}$; b) Chromatogram after purification; c) MS spectrum of the peak.

HR-MS $(E S I,+e V): m / z=1073.5163$ (calculated for $\left.[M+H]^{+}\right) ; 1073.5172$ (found).

${ }^{1} \mathrm{H}-\mathrm{NMR}$ (300 MHz, D $\left.{ }_{2} \mathrm{O}\right)$ ס: 0.59-0.84 (m, 14H, Leu i-Bu x2, Leu-CH- x2), 1.15-1.35 (m, 4H, Leu-CH $2.38\left(\mathrm{~m}, 12 \mathrm{H}\right.$, Glu x2, Gln), 2.97-3.43 (m, 6H, His- $\mathrm{CH}_{2-} \times 2$, Trp- $\left.\mathrm{CH}_{2-}\right), 3.80-4.70(\mathrm{~m}, 8 \mathrm{H}, \mathrm{H})$ ), 7.11-7.18 (m, 2H, $\mathrm{His}-\mathrm{CH}=\mathrm{x} 2), 7.18-7.37(\mathrm{~m}, 3 \mathrm{H}, \operatorname{Trp}-\mathrm{CH}=\mathrm{x} 2, \operatorname{Trp}-\mathrm{CH}=), 7.40-7.69(\mathrm{~m}, 2 \mathrm{H}, \operatorname{Trp}-\mathrm{CH}=x 2), 8.67(\mathrm{~s}, 2 \mathrm{H}, \mathrm{His}-\mathrm{CH}=$ x2) ppm.

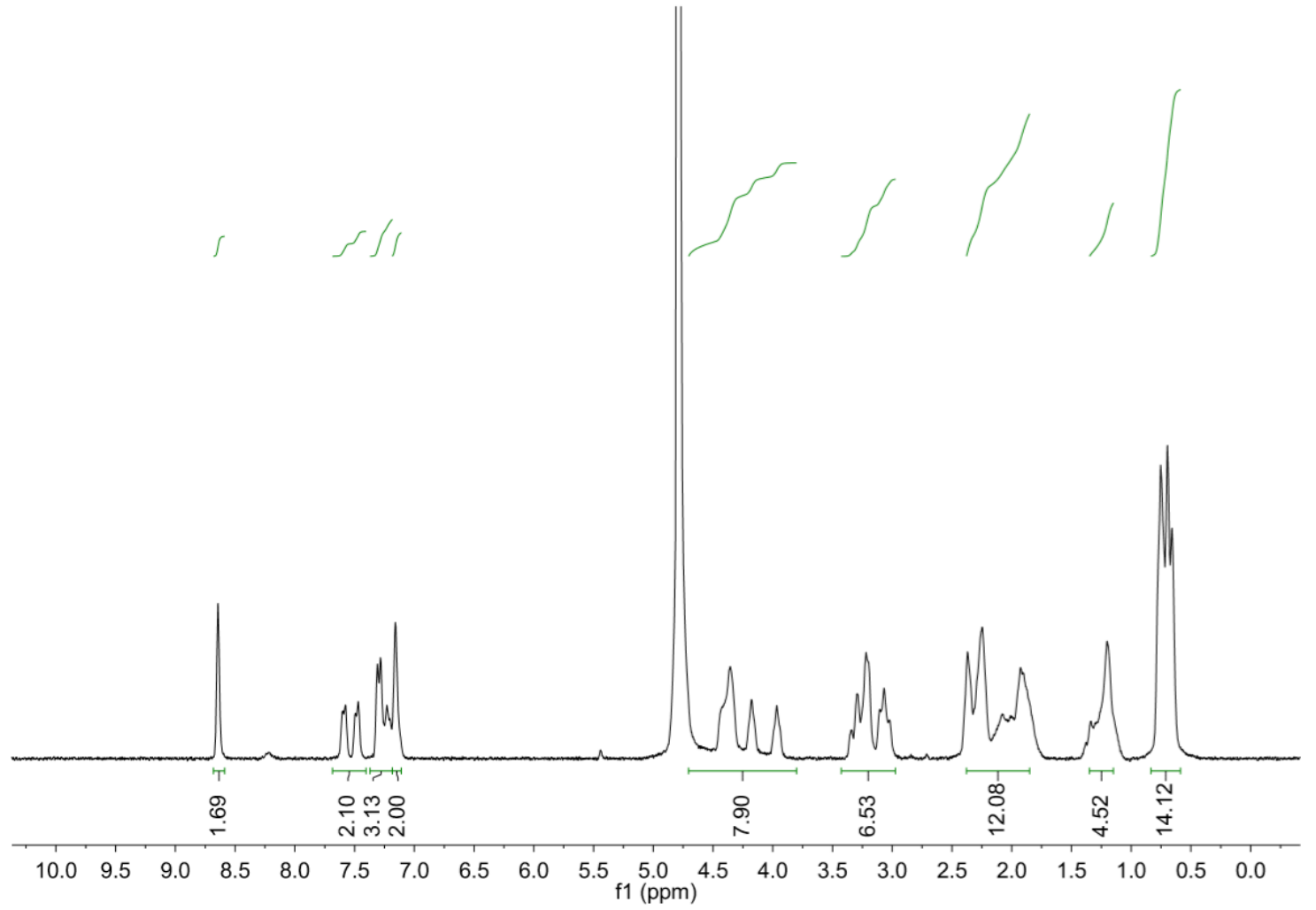

Figure S12. ${ }^{1} \mathrm{H}$ NMR $\left(300 \mathrm{MHz}\right.$ ) of $\mathrm{CP}_{\mathrm{oE}}$ in $\mathrm{D}_{2} \mathrm{O}$. 


\section{7. $\mathrm{CP}_{2 \mathrm{E} 2 \mathrm{H}}$}

UHPLC-MS (C18-ESI, +eV) A = $\mathrm{H}_{2} \mathrm{O}+0.1 \%$ TFA; $B=A C N+0.1 \%$ TFA; Gradient (A:B): 100:0 (0 min) $\rightarrow$ 25:75 $(21 \mathrm{~min}) ; R_{t}=11.0 \mathrm{~min} ; \mathrm{m} / \mathrm{z}=1073.5\left([\mathrm{M}+\mathrm{H}]^{+}\right), 537.4\left([\mathrm{M}+2 \mathrm{H}]^{2+}\right)$.
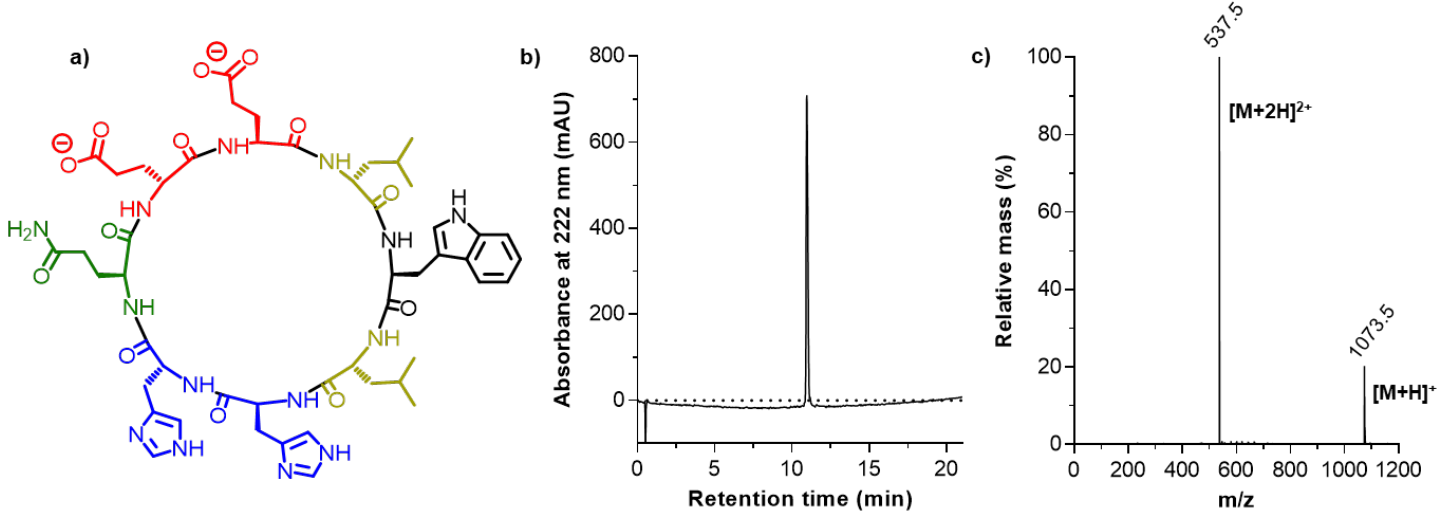

Figure S13. a) Structure of $\mathrm{CP}_{2 \mathrm{E} 2 \mathrm{H}}$; b) Chromatogram after purification; c) MS spectrum of the peak.

HR-MS $(E S I,+e V): m / z=1073.5163$ (calculated for $\left.[M+H]^{+}\right) ; 1073.5155$ (found).

${ }^{1} \mathrm{H}-\mathrm{NMR}\left(300 \mathrm{MHz}, \mathrm{D}_{2} \mathrm{O}\right)$ ס: 0.49-0.82 (m, 14H, Leu i-Bu x2, Leu-CH- x2), 1.18-1.37 (m, 4H, Leu-CH2- x2), 1.86$2.38\left(\mathrm{~m}, 12 \mathrm{H}\right.$, Glu x2, Gln), 2.87-3.38 (m, 6H, His- $\mathrm{CH}_{2}-\mathrm{x} 2$, Trp- $\left.\mathrm{CH}_{2-}\right)$, 3.83-4.69 (m, 8H, $\left.\mathrm{H}_{\alpha}\right)$, 6.95-7.37 (m, 2H, His-CH=x2, 3H, Trp-CH= x3), $7.48(\mathrm{~d}, J=7.5 \mathrm{~Hz}, 1 \mathrm{H}, \operatorname{Trp}-\mathrm{CH}=), 7.61(\mathrm{~d}, J=7.5 \mathrm{~Hz}, 1 \mathrm{H}, \operatorname{Trp}-\mathrm{CH}=), 8.62(\mathrm{~s}$, $2 \mathrm{H}, \mathrm{His}-\mathrm{CH}=\mathrm{x} 2) \mathrm{ppm}$.

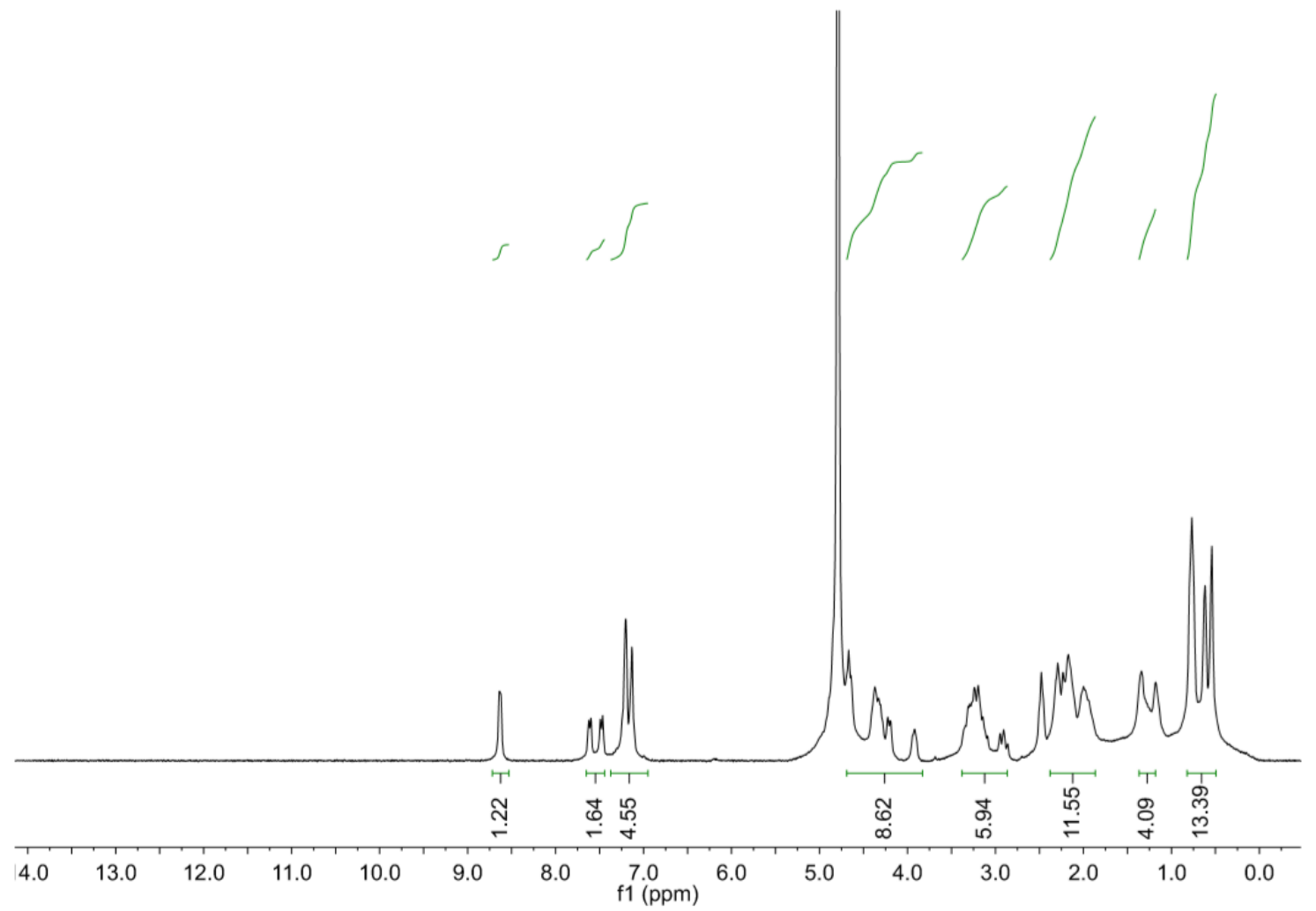

Figure S14. ${ }^{1} \mathrm{H}$ NMR $(300 \mathrm{MHz})$ of $\mathrm{CP}_{2 \mathrm{E} 2 \mathrm{H}}$ in $\mathrm{D}_{2} \mathrm{O}$. 


\section{8. $\quad \mathrm{CP}_{\mathrm{K}}$}

UHPLC-MS (C18-ESI, +eV) A = $\mathrm{H}_{2} \mathrm{O}+0.1 \%$ TFA; $B=A C N+0.1 \%$ TFA; Gradient (A:B): 100:0 (0 min) $\rightarrow$ 25:75 $(21 \mathrm{~min}) ; R_{t}=11.2 \mathrm{~min} ; \mathrm{m} / \mathrm{z}=1055.6\left([\mathrm{M}+\mathrm{H}]^{+}\right), 528.4\left([\mathrm{M}+2 \mathrm{H}]^{2+}\right)$.
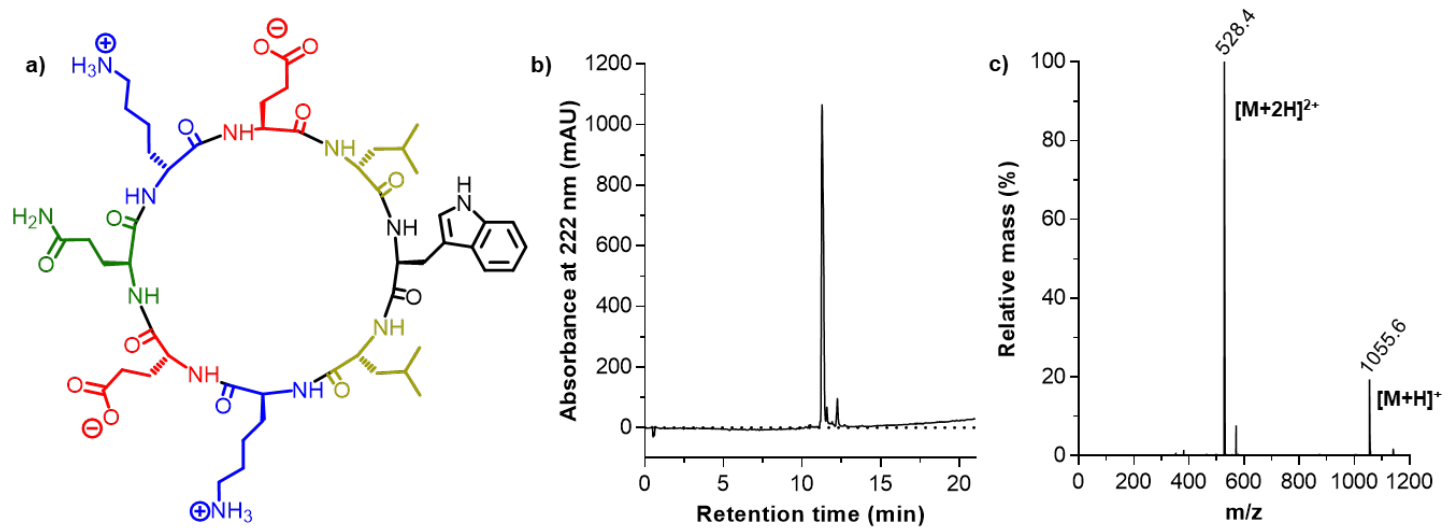

Figure S15. a) Structure of $\mathbf{C P}_{\mathbf{K}}$; b) Chromatogram after purification; c) MS spectrum of the peak.

HR-MS (ESI, +eV): m/z = 1055.5884 (calculated for $\left.[M+H]^{+}\right) ; 1055.5877$ (found).

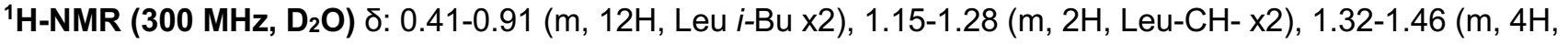
Leu-CH $2-x 2), 1.47-2.38$ (m, 24H, Glu x2, Lys- $\left.\mathrm{CH}_{2}-\mathrm{x} 6, \mathrm{Gln}\right), 2.88-3.02(\mathrm{~m}, 4 \mathrm{H}$, Lys-CH2- x2), 3.19-3.35 (m, 2H, Trp- $\left.\mathrm{CH}_{2-}\right), 4.10-4.66\left(\mathrm{~m}, 8 \mathrm{H}, \mathrm{H}_{\mathrm{a}}\right), 7.04-7.29(\mathrm{~m}, 3 \mathrm{H}, \mathrm{Trp}-\mathrm{CH}=\mathrm{x} 3), 7.47-7.70(\mathrm{~m}, 2 \mathrm{H}, \mathrm{Trp}-\mathrm{CH}=\mathrm{x} 2)$ ppm.

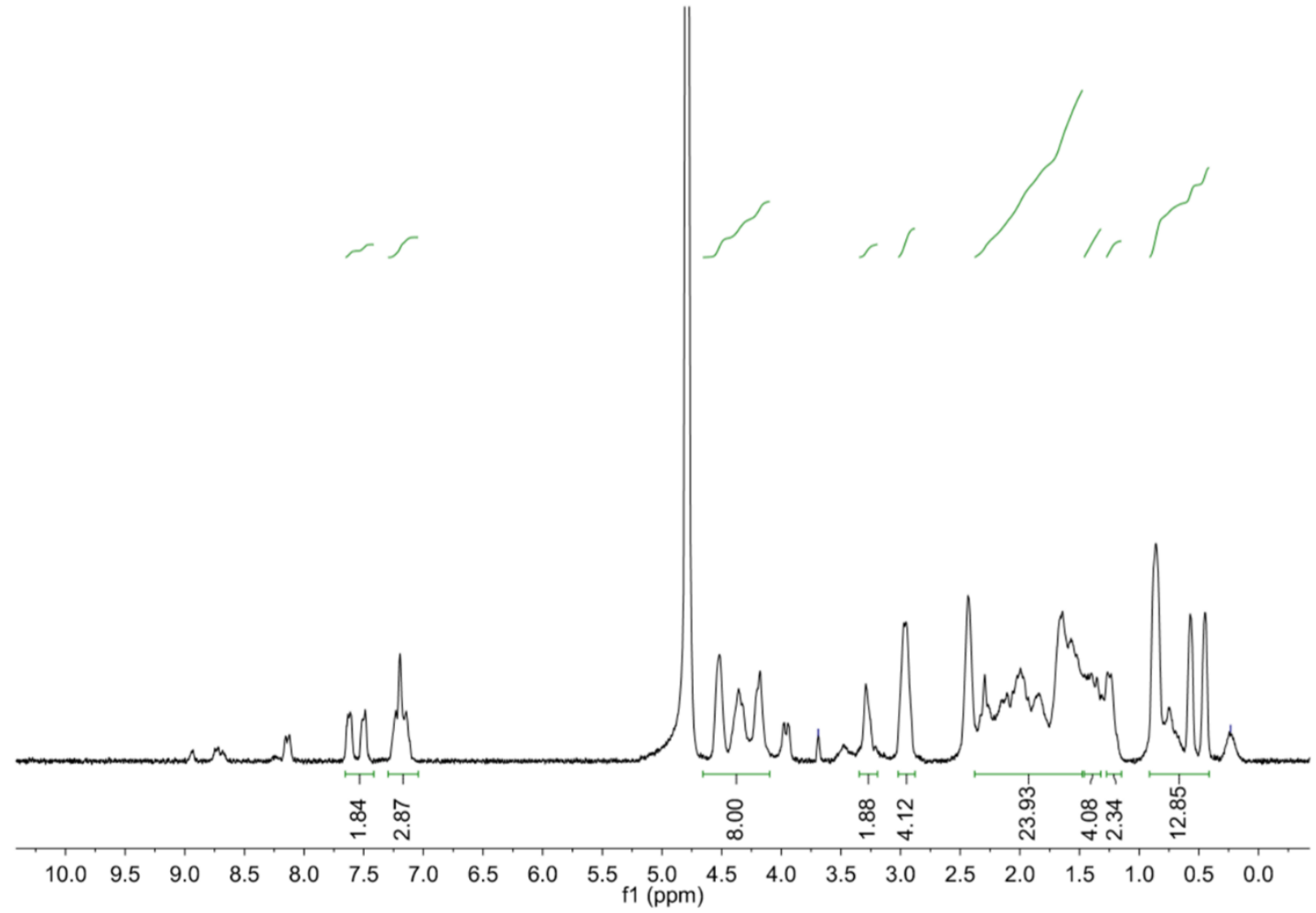

Figure S16. ${ }^{1} \mathrm{H}$ NMR $(300 \mathrm{MHz})$ of $\mathrm{CP}_{\mathrm{K}}$ in $\mathrm{D}_{2} \mathrm{O}$. 


\section{9. $\mathrm{CP}_{4 \mathrm{E}}$}

UHPLC-MS (C18-ESI, +eV) A = $\mathrm{H}_{2} \mathrm{O}+0.1 \%$ TFA; $\mathrm{B}=\mathrm{ACN}+0.1 \% \mathrm{TFA} ; 100: 0(0 \mathrm{~min}) \rightarrow 25: 75(21 \mathrm{~min}) ; R_{t}=$ $12.2 \mathrm{~min} ; \mathrm{m} / \mathrm{z}=1057.5\left([\mathrm{M}+\mathrm{H}]^{+}\right), 529.4\left([\mathrm{M}+2 \mathrm{H}]^{2+}\right)$.
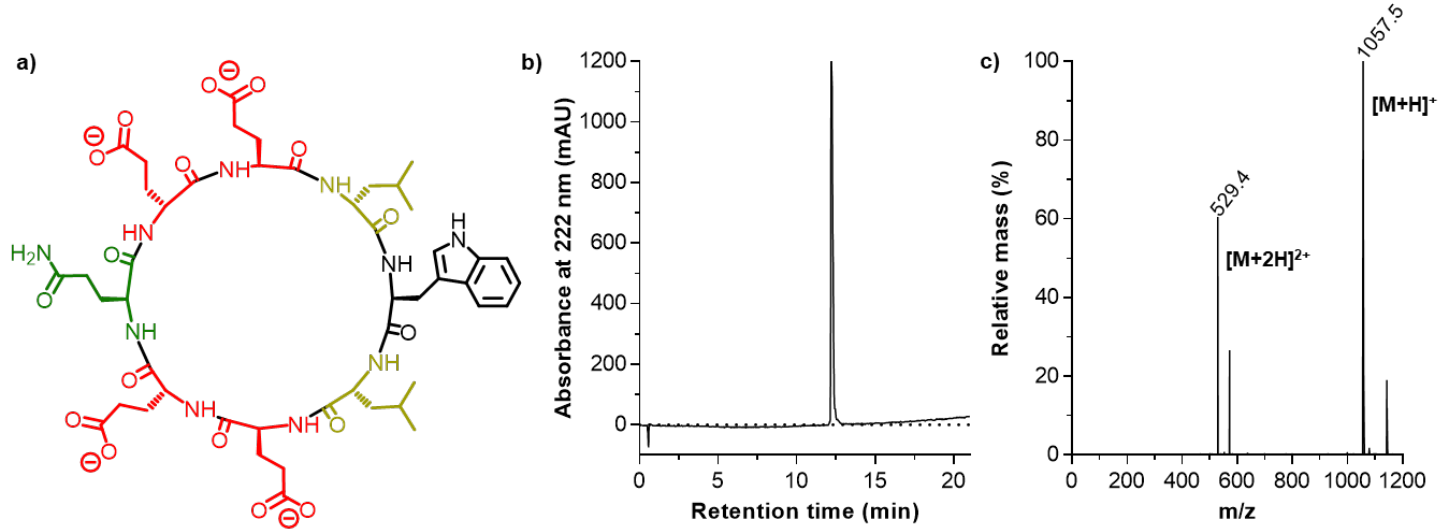

Figure S17. a) Structure of $\mathrm{CP}_{4 \mathrm{E}}$; b) Chromatogram after purification; c) MS spectrum of the peak.

HR-MS (ESI, +eV): m/z = 1057.4837 (calculated for $[M+H]^{+}$); 1057.4836 (found).

${ }^{1} \mathrm{H}-\mathrm{NMR}$ (300 MHz, D ${ }_{2} \mathrm{O}$ ) $\delta:$ 0.65-0.81 (m, 12H, Leu i-Bu x2), 1.20-1.29 (m, 2H, Leu-CH- x2), 1.34-1.46 (m, 4H, Leu- $\left.\mathrm{CH}_{2}-\mathrm{x} 2\right), 1.87-2.43\left(\mathrm{~m}, 2 \mathrm{H}\right.$, Glu x4, Gln), 3.12-3.36 (m, 2H, Trp-CH$\left.-\mathrm{CH}_{2}\right), 4.01-4.43\left(\mathrm{~m}, 8 \mathrm{H}, \mathrm{H}_{\mathrm{\alpha}}\right)$, 7.03-7.34 $(\mathrm{m}, 3 \mathrm{H}, \mathrm{Trp}-\mathrm{CH}=\mathrm{x} 3), 7.47-7.69(\mathrm{~m}, 2 \mathrm{H}, \mathrm{Trp}-\mathrm{CH}=\mathrm{x} 2) \mathrm{ppm}$.

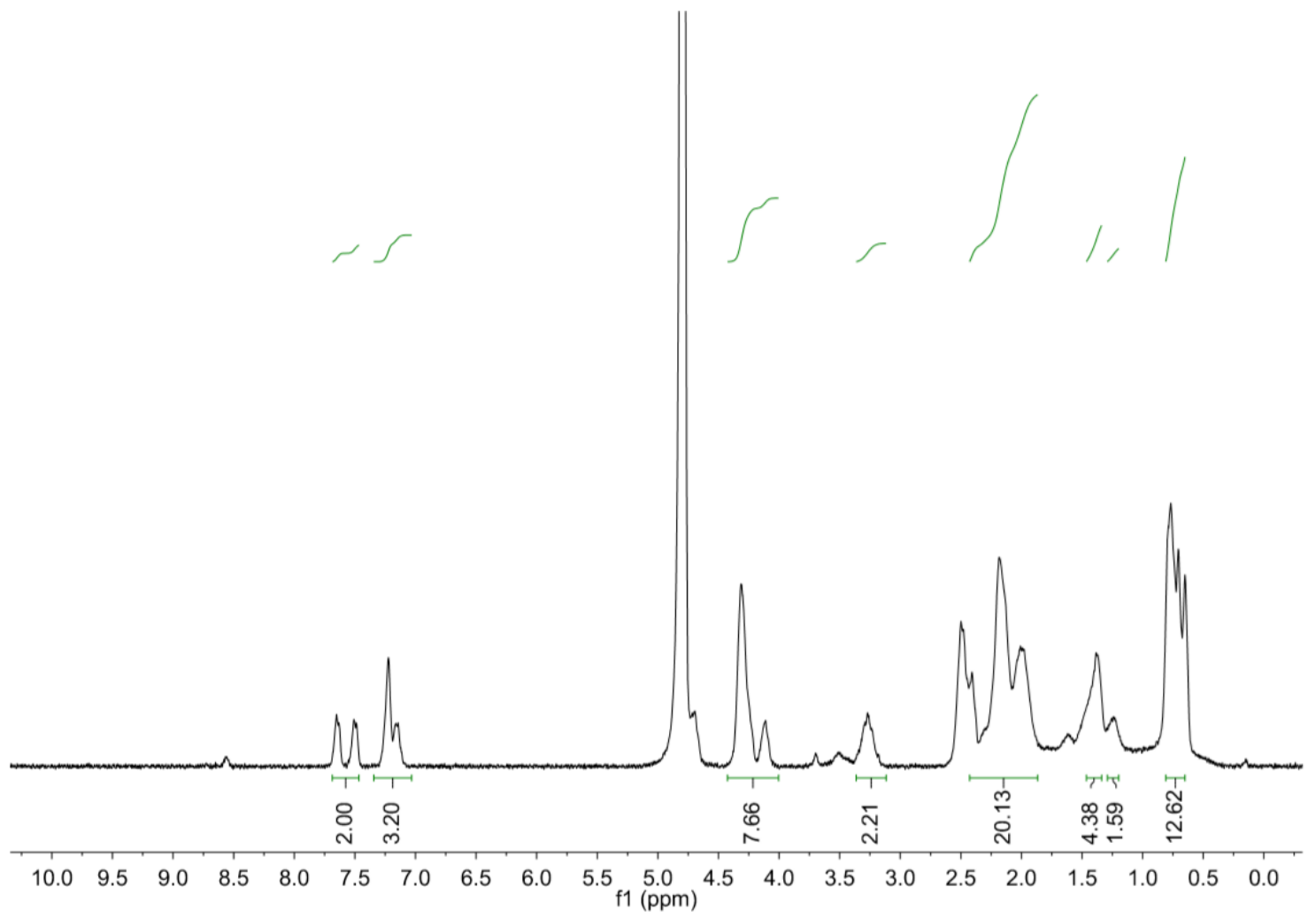

Figure S18. ${ }^{1} \mathrm{H}$ NMR $(300 \mathrm{MHz})$ of $\mathrm{CP}_{4 \mathrm{E}}$ in $\mathrm{D}_{2} \mathrm{O}$. 
5. Cyclic peptide self-assembly versus $\mathrm{pH}$ and $\mathrm{NaCl}$
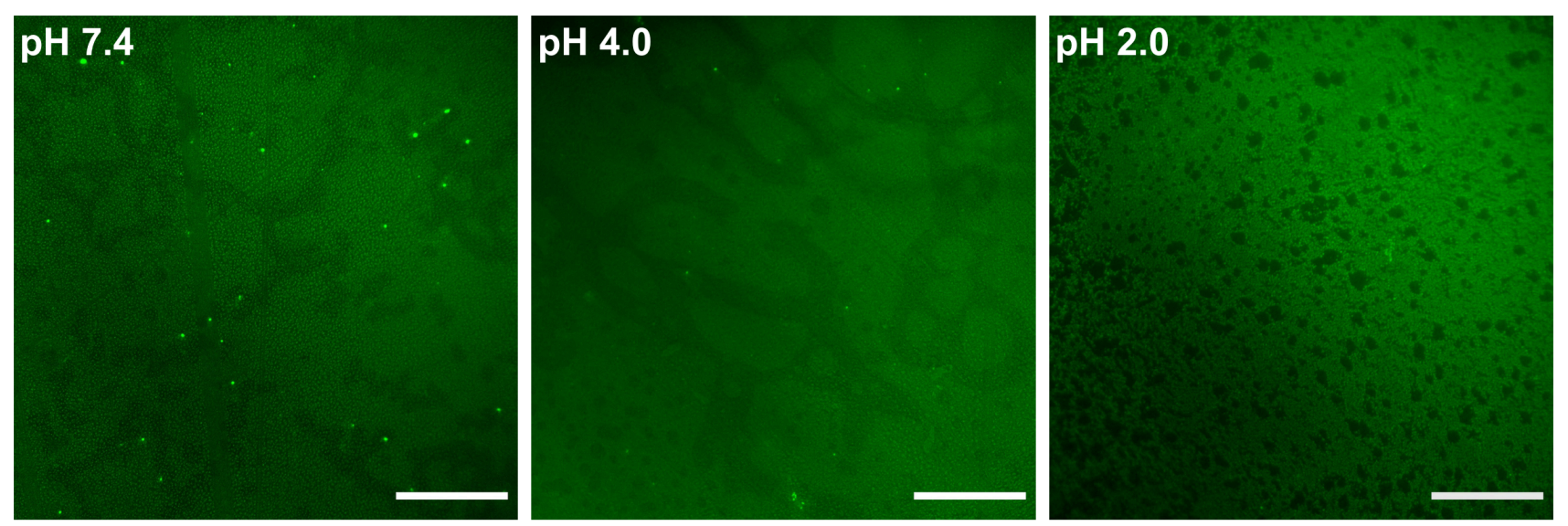

Figure S19. Epifluorescence micrographs of $\mathrm{CP}_{2 \mathrm{E} 2 \mathrm{H}}$ in $20 \mathrm{mM}$ sodium phosphate buffer adjusted at $\mathrm{pH} 7.4,4.0$ or 2.0 (see insets) in presence of thioflavin- $\mathrm{T}(10 \mu \mathrm{M})$. Scale bars $=50 \mu \mathrm{m}$.
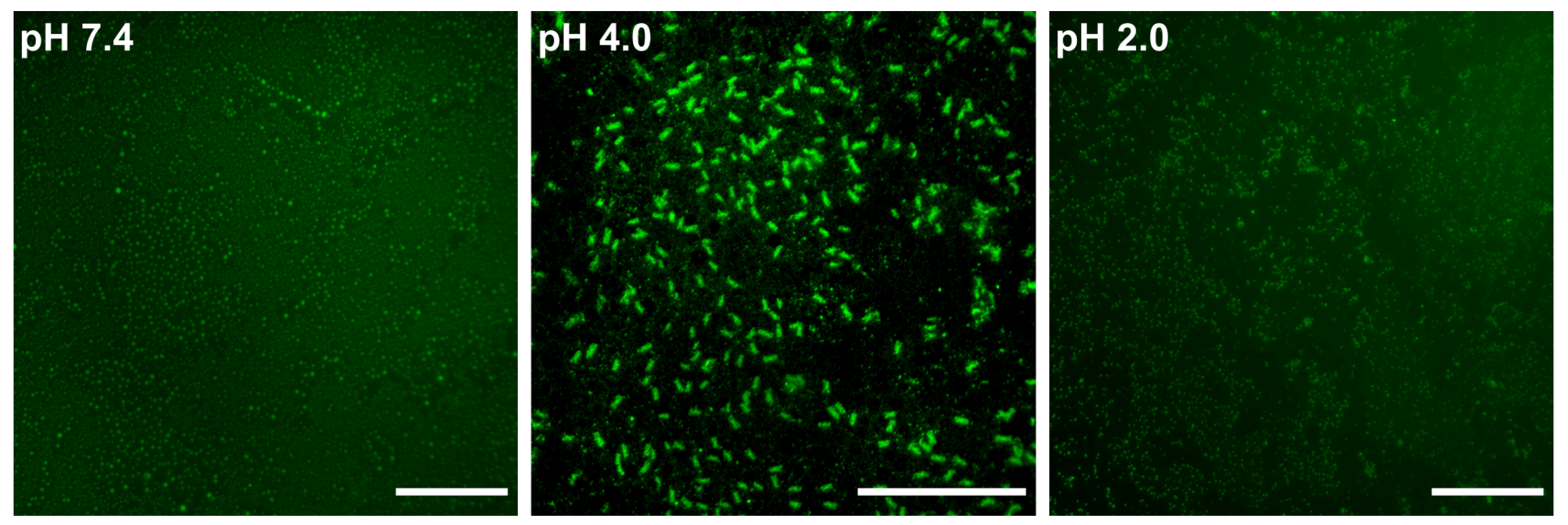

Figure S20. Epifluorescence micrographs of $\mathrm{CP}_{4 \mathrm{E}}$ in $20 \mathrm{mM}$ sodium phosphate buffer adjusted at $\mathrm{pH} 7.4,4.0$ or 2.0 (see insets) in presence of thioflavin- $\mathrm{T}(10 \mu \mathrm{M})$. Scale bars $=50 \mu \mathrm{m}$. 

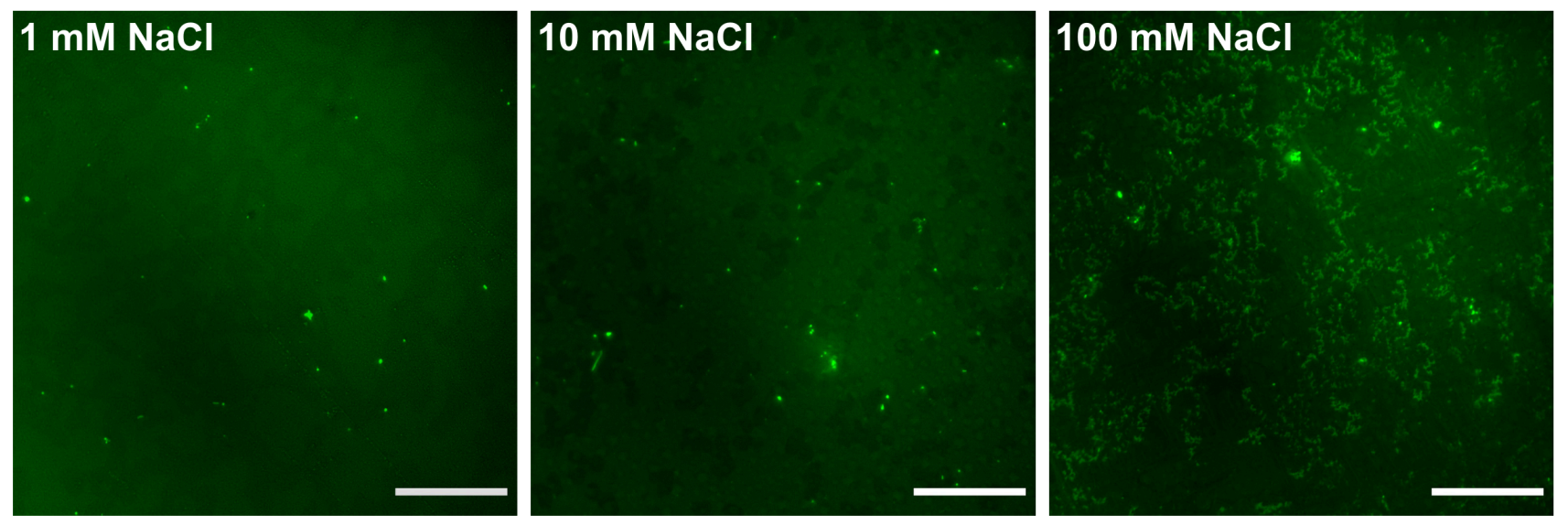

Figure S21. Epifluorescence micrographs of $\mathrm{CP}_{2 \mathrm{E} 2 \mathrm{H}}$ in $20 \mathrm{mM}$ sodium phosphate buffer at $\mathrm{pH} 7.4$ with increasing concentrations of $\mathrm{NaCl}$ (see insets) in presence of thioflavin- $\mathrm{T}(10 \mu \mathrm{M})$. Scale bars $=50 \mu \mathrm{m}$.
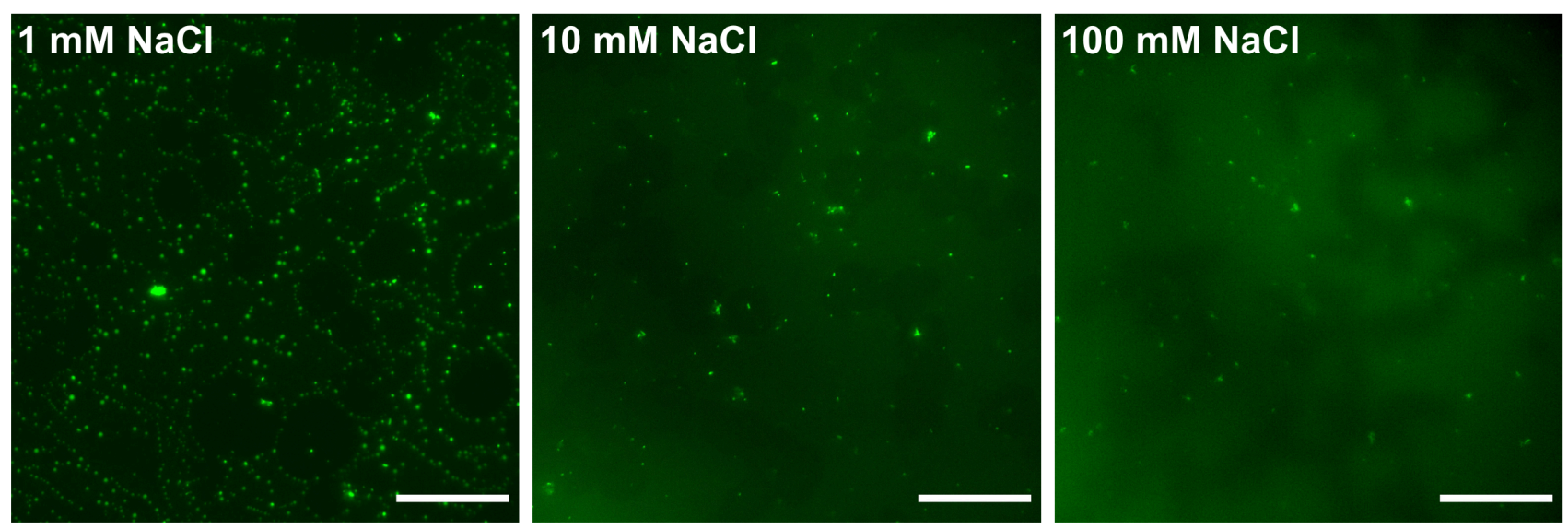

Figure S22. Epifluorescence micrographs of $\mathrm{CP}_{4 \mathrm{E}}$ in $20 \mathrm{mM}$ sodium phosphate buffer at $\mathrm{pH} 7.4$ with increasing concentrations of $\mathrm{NaCl}$ (see insets) in presence of thioflavin- $\mathrm{T}(10 \mu \mathrm{M})$. Scale bars $=50 \mu \mathrm{m}$. 